\title{
Erratum to: The Family Check-Up and Service Use in High-Risk Families of Young Children: A Prevention Strategy with a Bridge to Community-Based Treatment
}

Patty Leijten • Daniel S. Shaw • Frances Gardner •

Melvin N. Wilson • Walter Matthys • Thomas J. Dishion

Published online: 5 March 2015

(C) Society for Prevention Research 2015

Erratum to: Prev Sci

DOI 10.1007/s11121-014-0479-x

Authors' Statement of Conflict of Interest Dr. Thomas

J. Dishion is the developer of the Family Check-up

Program. No other authors have conflicts to disclose.

The online version of the original article can be found at http://dx.doi.org/ 10.1007/s11121-014-0479-x.

P. Leijten $(\bowtie) \cdot$ W. Matthys

Utrecht University, Utrecht, Netherlands

e-mail: p.leijten@uva.nl

D. S. Shaw

University of Pittsburgh, Pittsburgh, PA, USA

P. Leijten · F. Gardner

University of Oxford, Oxford, United Kingdom

M. N. Wilson

University of Virginia, Charlottesville, VA, USA

W. Matthys

University Medical Center Utrecht, Utrecht, Netherlands

T. J. Dishion

Arizona State University, Phoenix, AZ, USA

Present Address:

P. Leijten

University of Amsterdam, Amsterdam, Netherlands 